\title{
Apropriações sociais da tecnologia: ética e netiqueta no universo da infocomunicação
}

\author{
Technology social appropriates: ethics and netiquette in the infocommunicational universe
}

\begin{abstract}
Ana Carolina Silva Biscalchin
Mestranda do Programa de Pós-Graduação em Ciência da Informação da ECA/USP.

E-mail: anacarolb@usp.br

Marco Antonio de Almeida

Doutor em Ciências Sociais pela UNICAMP.

Professor do curso de Ciências da Informação e da Documentação da FFCLRP/USP e do PPGCI - ECA/USP.

E-mail: marcoaa@ffclrp.usp.br
\end{abstract}

\section{Resumo}

O artigo enfoca como a relação tecnologia-sociedade foi pensada na teoria social: quase sempre um dos pólos foi privilegiado às custas do outro. Procura-se mostrar as insuficiências desse tipo de abordagem, propondo pensar numa relação de co-determinação, na linha de Latour e Miège. São abordadas questões relativas à ética e ao comportamento dos indivíduos nos blogs para ilustrar as potencialidades dessa abordagem. Finalmente, observase a incipiência desse tipo de estudo na área de CI, e são referidos alguns dos desafios teóricos e metodológicos que eles apontam.

Palavras-Chave: Informação. Comunicação. Ética. Tecnologia. Teoria Social.

\begin{abstract}
The article focuses on how the relationship between technology and society was thought in social theory: almost always one of the poles was privileged at the expense of another. Attempts to show the shortcomings of this approach, proposing to think of a relationship of co-determination, in line with Latour and Miège. Some questions related to ethics and behavior of individuals in the blogs to illustrate the potential of this approach. Finally, there is a incipience of such studies in the area of IC, and are referred to some of the theoretical and methodological challenges which they point.
\end{abstract}

Keywords: Information. Communication. Ethics. Technology. Social Theory.

\section{Tecnologia \& Sociedade: uma relação ambígua}

Estabelecer as relações de mútua determinação (ou co-determinação) entre estruturas sociais e mudanças científicas e tecnológicas nunca foi tarefa fácil para os pensadores que se debruçaram sobre o tema. A tentação de estabelecer um peso maior para um dos pólos dessa equação sempre está presente, fazendo com que as análises tendam para dois pólos opostos que Bruno Latour (2001) denomina de "análises de conteúdo" e "análises de contexto". 
As "análises de conteúdo" privilegiariam o movimento puro das ideias, as transformações dos conceitos. São representadas pelas obras clássicas de historiografia da ciência que apresentam seu desenvolvimento como uma progressão linear, baseada na superação de conceitos apoiada em novas descobertas. Já as "análises de contexto" concentrariam seu foco nas pressões e demandas sociais sobre o trabalho científico, transformando o desenvolvimento da Ciência em pura corrente de transmissão das demandas que cada conjuntura imporia ao campo. Um bom exemplo desse tipo de análise, bastante comum, infelizmente, é a banalização das ideias de Bourdieu em estudos que atribuem um papel secundário aos conceitos e discussões teóricas, reduzindo-se a dinâmica do campo à interação estratégica entre seus atores, via de regra pela disputa político-institucional. Possibilita a compreensão de alguns casos específicos, mas não vislumbra o horizonte mais amplo do debate. Em conjunto, essas duas formas de abordar as mudanças científicas e técnicas produziriam, na perspectiva de Latour, um retrato esquizofrênico das transformações pelas quais passou a ciência. Uma forma de tentar escapar a essa dicotomia que reduz a complexidade do real seria lançar mão do conceito de mediação.

Embora o conceito de mediação seja bastante complexo, tanto nas suas apropriações pelas Ciências Sociais como pela Ciência da Informação, não iremos nos debruçar especificamente sobre ele nesse texto (para tanto, vide DAVALLON, 2007; ALMEIDA, 2008). Entretanto, vale destacar seu valor estratégico para abordar as relações entre mudança social e mudança tecnocientífica para fugir da oposição maniqueísta apontada por Latour. Outros pensadores reforçam essa perspectiva, como, por exemplo, Michael Callon, Bernard Miége ou Josiane Joüet. Esta última defende uma abordagem dessas transformações baseada na idéia de uma "dupla mediação", que "é ao mesmo tempo técnica, pois a ferramenta utilizada estrutura a prática, mas a mediação também é social, porque os motivos, as formas de uso e o sentido atribuído à prática se alimentam no corpo social" (JOÜET, 1997, p. 293).

Na busca de refletir acerca de uma abordagem que considere a "dupla mediação", vale destacar a contribuição de Bernard Miége para o tema, especialmente ao enfocar as tecnologias de informação e comunicação (TICs). No seu entender, para abordar a questão da inovação sociotécnica em matéria de TICs é necessário atentar para duas linhas de força convergentes e complementares: a-) as determinações da ordem da esfera técnica; b-) os processos que contribuem para o "enraizamento" social das TICs. (MIÈGE, 2009). Com relação a esse último aspecto, Miége utiliza o termo "enraizamento" social das TICs com cautela, alertando para o risco de soar um pouco ambíguo, ao dar a entender que a tecnologia 
seria algo produzido num lugar fora do social e para lá transplantado posteriormente - o que seria contraditório com sua perspectiva. Na realidade, com esse termo Miège pretende apontar para os fatores que levam os indivíduos a se apropriar das tecnologias, incorporando-as ao seu cotidiano, num processo que muitas vezes implica na combinação da reconfiguração de novos usos para as ferramentas e na criação de novos hábitos e atitudes sociais.

Essa apropriação sociocultural da tecnologia envolveria, na sua perspectiva, uma série de processos. Ele aponta sete: a-) a informacionalização; b-) a mediatização da comunicação; c-) a ampliação do domínio midiático; d-) a mercantilização das atividades comunicacionais; e-) A generalização das relações públicas; f-) a diferenciação das práticas; g-) a circulação dos fluxos e a transnacionalização das atividades. (MIÉGE, 2009) Em conjunto, estes processos podem ser entendidos como "lógicas sociais" da informação-comunicação, que, embora possuam, de certa forma, uma dinâmica própria, independente das TICs, recebem delas, por outro lado, impulsos dinâmicos que as vão conformando no decorrer do tempo.

A perspectiva de Miège aponta a importância de tentar enlaçar e combinar os níveis "macro" e "micro" da análise num mesmo movimento de compreensão do real. De um lado, considerar a dimensão política, econômica e social das atividades infocomunicacionais que implicam nas inovações e experimentações de novos suportes e ferramentas. De outro lado, não perder de vista a articulação entre as TICs e a produção de mensagens e sentido, bem como o "enraizamento" social das tecnologias traduzido, entre outras, pela atividade dos usuários-consumidores no aperfeiçoamento dos dispositivos e ferramentas. Um ensaio de utilização dessa perspectiva na compreensão da relação entre as TICs e seu "enraizamento" social será tentado a seguir, a partir de algumas considerações sobre o fenômeno dos blogs, com particular ênfase no processo de construção de códigos de comunicação e de conduta entre seus usuários.

\section{TICs e relações sociais: ética e netiqueta}

A Internet, nascida em 1969, a partir da Arpanet e aperfeiçoada durante a década de 1980, tornou-se popular e sua utilização cresceu exponencialmente desde então. Em si, a Internet não contém as informações, ela propicia a interconexão das redes. As redes e os equipamentos ligados a ela podem executar processos de vários tipos, além de armazenar documentos e dados. A maioria dos processos, documentos e dados são privados para a 
organização ou indivíduo, mas uma quantidade extremamente grande, e sempre em crescimento, é acessível ao público. Há também o enorme potencial comunicacional que a interconexão em redes proporcionou a seus usuários, e que é considerada como o fator que permite às redes exercer sua flexibilidade e adaptabilidade, afirmando assim, sua natureza revolucionária. Desse modo, novas formas de lidar com a informação são construídas, repensadas e apropriadas conforme o contexto sociocultural, implicando em discussões processuais e de conduta que conduzem ao debate da ética nos meios informacionais.

Para Gilberto Dupas, se instala um paradoxo nas sociedades pós-modernas, pois "ao mesmo tempo que elas se libertam dos valores de referência, a demanda por ética e preceitos morais parece crescer indefinidamente", e tanto a ética como a moral estão ligados à ideia de modos de agir determinados pelo uso. Mas a ética "seria uma 'metamoral' e não um conjunto de regras próprias de uma cultura. Ela se esforça em descer até os fundamentos ocultos da obrigação; pretende-se enunciadora de princípios ou de fundamentos últimos." (DUPAS, 2001, p.76). Assim, a ética que é ligada aos modos de agir se esforça por enunciar seus fundamentos.

Mas, entre as tarefas da ética não figura somente o esclarecimento e sua própria fundamentação, mas a aplicação de suas descobertas aos diferentes âmbitos da vida social. Cortina e Martinez (2005) elaboram uma proposta de ética aplicada que desfruta de uma circularidade própria de uma hermenêutica crítica, onde nos diferentes campos da vida social se detecta como base o princípio ético do reconhecimento de cada pessoa como interlocutor válido, sendo que esse princípio se modula de forma diferente em cada âmbito. É preciso contar com a institucionalização desse princípio em todos os campos da ética aplicada como a saúde, a economia, a tecnologia, os meios de comunicação, as organizações, as instituições sociais e políticas, as atividades profissionais, etc. Não convém então, fazer uma aplicação mecânica dos princípios éticos sem levar em conta que cada atividade tem suas próprias exigências morais e valores específicos, e que os afetados pelas normas em todas as atividades sociais são interlocutores válidos.

A Internet como um meio informacional também possui suas peculiaridades, como o uso preponderante da escrita e a inserção da multimídia inaugurando novas formas de interações na comunicação mediada por computador. Nesse âmbito, as regras e normas de conduta sofrem as adaptações pertinentes em conformidade com suas necessidade de moldar as práticas ao que seria eticamente aceito pela sociedade. $\mathrm{O}$ mecanismo mais evidente dessas 
mudanças são os acordos elaborados sobre como se portar no espaço virtual. As etiquetas, diretrizes de comportamento que se revelam a batuta regente das relações, foram rapidamente popularizadas por possuírem um alcance abrangente pela condensação de ideias em geral bem aceitas.

Ética e etiqueta possuem sentidos diferentes, mas são termos intimamente ligados. A etiqueta é definida como o conjunto de atitudes e comportamentos dos indivíduos em seu diaa-dia; são regras, normas e estilo visando facilitar o relacionamento e a convivência em sociedade. Alguns até dizem que a etiqueta é uma "pequena ética", contudo a etiqueta, mais que um resumo pronto da ética, demonstra a aplicabilidade desta, uma vez que muda conforme o âmbito e seus interlocutores.

A etiqueta pode ser encarada como uma forma cultural que reflete o comportamento social esperado em contextos específicos, perfilando-se, dessa maneira, ao lado de outros mecanismos de controle social. Norbert Elias (1990), em sua obra "A sociedade de Corte", utiliza o estudo da etiqueta como exemplo desse tipo específico de controle social. Ele aponta que a estrutura cerimonial do palácio do rei Luiz XVI era planejada com a finalidade de legitimar o poder do rei e conservar a interdependência entre ele e a nobreza.

Vale aqui relembrar algumas observações de Berger e Luckmann (1974) que podem ser úteis para compreender a questão do controle nessa perspectiva. Para esses autores, as atividades humanas, de um modo geral, estão sujeitas ao hábito, à padronização. $\mathrm{O}$ estreitamento de opções liberta o indivíduo do fardo de ter que tomar constantes decisões, tornando desnecessário que cada situação tenha que ser definida de novo, etapa por etapa. As rotinas e sub-rotinas habituais constituem-se assim num acervo geral de conhecimentos. Desse modo, a institucionalização é a tipificação de certas ações habituais. Deve-se atentar ao fato de que essas tipificações são compartilhadas e acessíveis aos membros do grupo social; a própria instituição tipifica os atores e as ações individuais. Além disso, as instituições possuem uma história e mecanismos de controle.

Embora do ponto de vista real as instituições se manifestam em coletividades que contém um número considerável de pessoas, teoricamente é possível afirmar que o processo de tipificação ocorreria mesmo entre dois indivíduos, somente (Um bom exemplo é dado por Robinson Crusoé e suas primeiras tentativas de se relacionar com Sexta-Feira). A previsibilidade das ações do outro elimina a surpresa e o perigo potencial que ele poderia representar, além de sedimentar a divisão social do trabalho e possibilitar o surgimento de 
inovações com a expansão desse mundo social.

As biografias individuais se inscrevem, se localizam, na história das instituições previamente consolidadas. A objetividade desse mundo institucional sempre é, no entanto, produto e construção do homem. A "objetivação" é o processo pelo qual os produtos exteriorizados da atividade humana ganham objetividade. A exteriorização e a objetivação são momentos de um processo dialético contínuo, ao qual vem se juntar posteriormente a "interiorização" - o processo pelo qual o mundo social objetivo é reintroduzido na consciência no curso da socialização. Ao mesmo tempo, o mundo institucional exige legitimação, isto é, modos pelos quais pode ser "explicado" e justificado.

Assim, se a integração de uma ordem institucional só pode ser explicada a partir do "conhecimento" que se tem dela, esse "conhecimento" se torna peça fundamental para a análise da ordem institucional em questão. Esse conhecimento não deve ser confundido com os sistemas teóricos (embora as teorias também façam parte dele). É a soma daquilo que "todos sabem", um corpus de conhecimento transmitido como receita por qualquer instituição. Ou seja, trata-se de formas de circulação de informação e produção de conhecimentos socialmente valorizados por possibilitar as interações e trocas entre os indivíduos.

A interação é definida por Goffman (2004) como um encontro que tem lugar em qualquer ocasião em que um conjunto de pessoas está em contínua presença mútua. Estes encontros, que eram face-a-face passaram a ser mediados pela tecnologia. Novos espaços públicos são construídos, como redes sociais, blogs, comunidades virtuais, fóruns, entre outros, resultando em áreas de interação social, em que se reproduzem o ritual dos eventos de interação. O conjunto de regras de comportamento na Internet, a netiqueta, tem origem na fusão das palavras net (em inglês - rede) e etiqueta (regras de comportamento - etiquette). A expressão traduz um conceito de bom uso da internet, sugestões e recomendações para usar as ferramentas emails, blogs, sites de relacionamento e demais ambientes virtuais.

O documento considerado fundador das regras de interação na rede, o "RFC1855, Diretrizes Netiqueta", foi desenvolvido por S. Hambridge (1995), engenheiro da Intel Corporation, publicado em 1995 (PATALANO, 2004). O "RFC1855" (1995) foi produzido pelo Uso Responsável da Rede (RUN) Working Group do IETF, Internet Engineering Task Force. O IETF é uma comunidade aberta internacional formada por designers, operadores, fornecedores e pesquisadores interessados na evolução da arquitetura da Internet e das 
operações. Esta organização é composta principalmente por engenheiros e seu modo de funcionamento é através de grupos de trabalho que usam as listas de discussão para se comunicar.

Ainda que muitos manuais de netiquetas possam ser consultados na internet, costumase considerar o livro "NETiquette" de Virginia Shea a versão definitiva destas regras; o livro foi publicado em 1994 e contém 10 regras básicas de comportamento na rede. As regras são as seguintes:

- $\quad$ Regra 1: Lembrar-se o ser humano;

- $\quad$ Regra 2: Aderir aos padrões de comportamento online;

- $\quad$ Regra 3: Saber onde você está no ciberespaço;

- Regra 4: Respeito ao tempo das outras pessoas e a largura de banda (capacidade de transferência de dados);

- $\quad$ Regra 5: Ter um bom perfil on-line;

- $\quad$ Regra 6: Compartilhar conhecimento especializado;

- $\quad$ Regra 7: Ajudar a manter os conflitos sob controle;

- $\quad$ Regra 8: Respeitar a privacidade das pessoas;

- $\quad$ Regra 9: Não abusar de seu poder;

- $\quad$ Regra 10: Perdoar os erros das outras pessoas.

(traduzido pelos autores, SHEA, 1994)

Atualmente, a maioria das trocas que ocorrem na Internet, para regularizar o fluxo de suas mensagens e interação entre os participantes, segue as regras estabelecidas pela "RFC1855", regras para: correio eletrônico, listas de discussão, chat e outros serviços de comunicação on-line mais recentes, como mensagens instantâneas e comunicação oral de pessoa para pessoa. Porém, novas configurações e adaptações podem ser encontradas a todo momento dependendo do interesse que cada grupo interconectado possui. Mesmo assim, há um apontamento para uma cultura comunitária virtual, que Castells (2003) sugere possuir valores como a importância da comunicação horizontal e livre, a liberdade de expressão, e a conectividade através das redes individuais como valores globais para os produtores da internet. Nesse sentido, as regras enunciadas pela "RFC1855" apontam para formas de controle social menos funcionalistas e instrumentais, lembrando a necessidade de pensar as muitas dimensões dos "complexos mecanismos que não propriamente controlam, mas, sobretudo, produzem comportamentos considerados adequados ou inadequados com relação a 
determinadas normas e instituições sociais.” (ALVAREZ, 2004, p. 170)

Apesar de algumas regras abordadas nas netiquetas poderem ser chamadas de regras éticas, muitas vezes o termo pode ser considerado mais "superficial" e remetido para a esfera da moda ou do comportamento. No entanto, questões éticas na comunicação são objeto das orientações das netiquetas, e as regras por trás dos guias de netiquetas não estão completamente explícitas. A maioria dos guias enfatiza a responsabilidade individual e o comportamento legal, mas oferecem apontamentos acerca do caminho escolhido como solução de problemas éticos ligados ao uso das novas tecnologias de comunicação e de informação. Porém, ao considerar que "as novas tecnologias da informação não são simplesmente ferramentas a serem aplicadas, mas processos a serem desenvolvidos" (CASTELLS, 1999. p.70), as regras devem ser entendidas como algo inacabado e também em desenvolvimento e construção junto com seu objeto de intervenção.

Novas formas de interação pedem novas regras de conduta, que advém do uso e da própria adequação que o indivíduo estabelece com a mediação. Essas interações mediadas obedecem regras (netiquetas) que vão sendo moldadas, construídas ou derrubadas em conformidade com a construção de novas identidades e de novas relações advindas da reflexividade do sujeito diante das novas tecnologias. Anthony Giddens afirma que uma das grandes características da vida social moderna é a acentuada reflexividade das práticas sociais, que são "constantemente examinadas e reformuladas à luz de informação renovada sobre estas próprias práticas, alterando assim constitutivamente seu caráter." (GIDDENS, 1991, p.45). A reflexividade sempre existiu, porém na modernidade ela se radicaliza, devido à rapidez de propagação da informação e da sistematização dos conhecimentos científicos. Porém, Giddens declara também, que os mecanismos de vigilância estão presentes como uma das principais dimensões institucionais da modernidade e que o controle indireto da informação é um dos pilares da concentração administrativa que caracteriza os estados modernos em geral (GIDDENS, 1991).

Nesse sentido, a análise das regras estabelecidas para facilitar as relações humanas mediadas pelo uso da internet constitui uma importante frente de investigação para compreender as relações de poder, ética e fatores sociais influentes na conduta mediada. 


\section{Inovação social e enraizamento social: o caso dos blogs brasileiros}

Um bom exemplo desse processo pode ser exemplificado pela dinâmica observada nos blogs. O termo blog surgiu da palavra "weblog", criada em dezembro de 1997 pelo norte americano Jorn Barger, que designava um conjunto de sites que colecionavam e divulgavam links na Web (BLOOD, 2000 apud MONTARDO, 2008). No início de 1999, Peter Merholz, separou essa palavra e criou o termo "we blog", ou "nós blogamos". Por fim o termo Blog se popularizou quando a empresa Pyra criou o serviço "Blogger" que facilitava a manutenção e publicação dos sites abrindo espaço ao utilizador que não precisava mais ter conhecimentos acerca da linguagem HTML. A apropriação da ferramenta deu-se nos mais diversos usos, mas o uso como diários pessoais foi a que difundiu-se mais rapidamente (CARVALHO, 2000, LEMOS, 2002).

Recuero (2004) afirma, a respeito dos weblogs:

weblogs constituem-se em um fenômeno da sociedade globalizada, frutos da
"cultura Internet" e de uma tentativa de apropriação individual e coletiva do
ciberespaço, através da extensão daquilo que o blogueiro compreende como seu
particular (identidade individual, personalidade) através da configuração de um
espaço. (RECUERO, 2004)

Os blogs são feitos por pessoas que compartilham ideias, motivações e interagem. Estas motivações podem ser contempladas por agregação de conteúdo de interesse comum, mas muitos blogueiros se ocupam em criar algo novo para compartilhar. Quando o autor do conteúdo o cria para veiculação em seu blog, esse conteúdo também está sob atenção dos direitos autorais. A replicação do mesmo deve ocorrer respeitando as especificações do que a lei de direitos autorais exige. Porém, a internet é um campo aberto ainda, assegurar-se de que seu conteúdo não será aproveitado de maneiras diversas da qual foi criado é praticamente impossível, portanto, perde-se o controle da criação e, muitas vezes, o próprio mérito da criação.

A constante preocupação dos criadores e usuários de blogs a respeito do uso e veiculação dos conteúdos levou à adoção de netiquetas, adaptando suas recomendações para lidar com seus interesses. A recomendação mais comum para inibir situações de plágio dentro da blogosfera brasileira é citar a fonte da informação utilizando um link em hipertexto direcionando ao autor do conteúdo. Essa regra pode ser vista em diversos metablogs que dão dicas e oferecem materiais de orientação para novos usuários da ferramenta. No Dicas 
Blogger ${ }^{1}$ por exemplo, o assunto "conteúdo" recebe a seguinte recomendação:

Não copie um post integralmente de outro blogueiro. Seja criativo. Divulgue as suas próprias ideias. Se a ideia do colega te agradou, desenvolva um texto com a sua cara! Mas se, mesmo assim, você quiser pegar algo deste post (imagens e tal) coloque a FONTE (Créditos) com o link do referido blog. (SARDINHA ,2008)

Assim, surgiram campanhas que adquiram visibilidade rapidamente como a campanha: "Usura não! - Campanha Treta contra a avareza e pão-duragem de links, por uma internet mais reciproca ${ }^{2}$ ". Diversos blogs de entretenimento se uniram aos ideais propostos rapidamente e os difundiram rede. A ideia central é a difusão do uso do link e a construção de hipertextos que direcionem o leitor para a fonte da informação.

Além da escrita e da leitura, existem outras formas de acesso e controle de hipertextos como a criação de links e conexão em rede. A possibilidade de criação coletiva de links é uma questão política (LANDOW, 1997 apud PRIMO, 2006). O link, não se pratica apenas como comunicação em rede entre os blogs, mas carrega consigo, neste contexto, também uma relação de respeito aos direitos autorais de determinado conteúdo, formalizando a relação entre pessoas pela ética da citação da fonte do conteúdo que está sendo veiculado.

Nessa perspectiva podemos refletir acerca do já mencionado processo de “enraizamento social” das TICs apontado por Miège (2009). A idéia de enraizamento social pode ser aproximada ao conceito de sedimentação (proposto por Alfred Schutz) e relaciona-se ao fato de que apenas uma pequena parte das experiências humanas é retida pela consciência: nesse sentido são "sedimentadas", isto é, passíveis de reconhecimento e de lembrança. Quando vários indivíduos participam de experiências comuns que constituem um acervo de conhecimento podemos falar de "sedimentação intersubjetiva". Os processos de legitimação das sedimentações coletivas não precisa necessariamente ser coerente com a reconstrução de seu processo original de formação, podendo constituir-se como uma "invenção da tradição" (como diria Eric Hobsbawm). Por outro lado, a transmissão do significado de uma instituição para os potenciais atores dessas ações institucionalizadas envolve algum tipo sistemático de processo "educacional" - mesmo que incorpore, em alguma medida, meios coercitivos. Os papéis sociais, nesse sentido, seriam a tipificação dos desempenhos dos indivíduos, que possibilitaria a comparação e o intercâmbio desses desempenhos sociais. Estoques comuns de conhecimentos e informações incluem os padrões esperados de desempenho de papéis. Esses

\footnotetext{
${ }^{1}$ http://www.dicasblogger.com.br/

${ }^{2}$ http://www.treta.com.br/usuranao
}

InCID: R. Ci. Inf. e Doc., Ribeirão Preto, v. 2, n. 1, p. 193-207, jan./jun. 2011. 
padrões são reforçados socialmente, esperando-se dos indivíduos uma "aderência" aos mesmos. Desse modo, há uma distribuição social do conhecimento e da informação: o que é geralmente relevante e o que é relevante somente para alguns papéis particulares. Em função da divisão do trabalho e da complexidade crescente das sociedades, o conhecimento de papéis específicos crescerá em proporção mais rápida que o conhecimento geralmente relevante e acessível (proporcionalmente ao aumento do número de especialidades e especialistas).

Dessa forma, o uso do link como netiqueta tornou-se exemplo de como são adaptadas as condutas e se pautam os debates das alternativas e das formas colaborativas de produção, disseminação e uso de informação, particularmente aquelas que usam a Internet, já que somente na rede é possível acessar rapidamente o conteúdo original ou a fonte por meio do hipertexto. O uso da internet requer não só novos enfoques da propriedade intelectual e do direito autoral, como também da construção de papéis sociais e de formas de relacionamento social entre os indivíduos e grupos mediada pela circulação da informação. Essa é uma discussão em voga, mas as soluções rápidas e amplamente adotadas pela cultura comunitária dos blogs de entretenimento tornam-se relevantes por serem eles uma das primeiras zonas de contato com a rede para os novos usuários. Nesse sentido, as netiquetas não pode ser relegadas a uma abordagem de fenômeno superficial ou da moda, pois carregam as decisões políticas de um determinado grupo e delimitam as condutas a serem adotadas, contribuindo ativamente no processo de enraizamento social das TICs.

E aqui poderíamos abordar outro tema caro ao universo da infocomunicação: a questão da validação da informação. No caso dos blogs, esse processo de validação relaciona-se diretamente ao capital social acumulado pelo Blog (e/ou seu blogueiro). Como observa Raquel Recuero (2009), para compreender os fluxos de informação dentro das redes sociais na internet, é necessário compreender os valores e as conexões estabelecidas pelos atores em cada um desses espaços, considerando assim como o capital social pode influenciar a difusão das informações. Fundamentalmente, as pessoas não publicam informações de maneira aleatória, mas baseadas na percepção de valor contido na informação divulgada:

Ou seja, parte da percepção de valor da atividade dos blogs pode estar na percepção dos comentários recebidos e do feedback de sua audiência. O capital social seria, assim, uma motivação fundamental para criar e manter um blog e poderia ser associado com diferentes padrões de fluxo de informação percebidos na blogosfera. E assim como nos blogs, nos demais sites das redes sociais a possibilidade é a mesma. Os atores são conscientes das impressões que desejam criar e dos valores e impressões que podem ser construídos nas redes sociais mediadas pelo computador. (RECUERO, 2009, p. 117-118)

InCID: R. Ci. Inf. e Doc., Ribeirão Preto, v. 2, n. 1, p. 193-207, jan./jun. 2011. 
Vale lembrar que há mais um complicador no caso dos blogs na internet em relação ao processo de validação das informações: não há um único tipo de reputação (isto em alguma medida, também vale para outras redes tecnosociais). Cada nó na rede pode construir diferentes tipos de reputação a partir de aspectos relacionais ou cognitivos, de acordo com a informação ou meme ${ }^{3}$ que divulga em seu perfil. Entram em jogo aqui não só conhecimentos especializados e qualificações específicas, mas também experiências e trajetórias de vida, além de competências e habilidades sociocomunicacionais.

\section{Considerações finais: a dupla mediação}

Do que foi exposto anteriormente, uma conclusão imediata pode ser observada: são necessários estudos de caso e estudos comparativos para levantar algumas característicaschave do novo ambiente de interações e levar em consideração, na medida em que surjam as evidências, de como se dá a auto-organização e auto-regulação na Internet. Isto levará a uma discussão de como se constroem e legitimam novos e adaptados mecanismos de controle social, a partir da maneira pelas quais as informações são produzidas, circulam e são apropriadas no contexto das TICs. Mas as perspectivas abertas por este debate podem ser expandidas para se avaliar suas conseqüências num plano propriamente epistemológico da Ciência da Informação.

O problema a ser enfrentado é análogo ao que, no campo das Ciências Sociais, José Maurício Domingos denominou pitorescamente de "cobertor curto": cobre-se a estrutura, mas a ação fica descoberta; dá-se atenção à memória social, mas a criatividade fica na penumbra ... enfim, em outras palavras, trata-se de conjugar, com consistência analítica, os níveis micro e macro da análise social. Domingues mostra as limitações das abordagens micro (como a fenomenologia e a etnometodologia) e das abordagens macro (como o funcionalismo e a teoria da estruturação) quando tomadas isoladamente. Uma combinação das duas abordagens, no seu entender, seria mais profícua em termos analíticos, e ele aponta como perspectiva promissora a noção de "subjetividades coletivas", que seriam entendidas como teias de interação, como elementos de mediação entre indivíduos e sociedade, "como a particularidade que faz a ligação entre aquela singularidade e esta generalidade, as quais

\footnotetext{
${ }^{3}$ O termo "meme" foi cunhado pelo biólogo Richard Dawkins, podendo ser definido como uma entidade capaz de ser transmitida de um cérebro a outro, e seu estudo está diretamente relacionado à compreensão acerca da forma como se dá a difusão da informação - quais tipos de idéia "sobrevivem" e são repassadas de pessoa à pessoa, e quais tipos de idéias caem no esquecimento.
} 
constitui e pelas quais é constituída" (DOMINGUES, 2001, p. 101, grifos do autor)

No caso da Ciência da Informação, os termos da equação poderiam ser expostos no jargão já consolidado da área: como combinar as abordagens mais focadas no meio técnico, (centrada nas linguagens e arquiteturas da informação), com as abordagens focadas nos sujeitos (estudos de usuários, de circulação e apropriação da informação) e as abordagens estruturais (relativas a sistemas e políticas da informação)?

Ao abordarmos o fenômeno da netiqueta nos blogs procuramos, a partir de um objeto sem tradição de estudos na CI, ensaiar uma abordagem que contemplasse questões habituais da área numa perspectiva menos estanque: produção e circulação da informação; estudos de usuários; validação da informação; ética no processo informacional. Muito ainda há por avançar, obviamente, pois a pesquisa está em seu início. De qualquer modo, pensamos que abordar fenômenos emergentes a partir das TICs reveste-se de particular importância para a área, mesmo que fujam do espectro delimitado pela tradição.

Trata-se, obviamente, de um grande desafio, a ser encarado de forma interdisciplinar e, preferencialmente, de forma coletiva. As sugestões presentes na perspectiva da "dupla mediação" apontadas por Miège no início desse texto são promissoras para uma abordagem dessa natureza (MIÈGE, 2009). No Brasil, algumas tentativas, ainda esporádicas, se considerado o conjunto da produção, apontam para esse caminho na Ciência da Informação. O trabalho de Marteleto e Stotz (2009), numa reunião de artigos a cargo de especialistas de diversas áreas, procura abarcar o fenômeno da produção, circulação e apropriação da informação em saúde em seus diversos níveis e contextos, tomando como foco a favela da Maré, no Rio de Janeiro. Também o trabalho de Maria Nélida Gonzalez de Gómez (2006) procura dar conta dos diversos níveis de análise, perpassando os planos epistemológico, tecnológico, político e lingüístico do fenômeno da informação mediada pelas tecnologias. Inspirados por estes trabalhos seminais, cabe aos pesquisadores da CI enfrentar os desafios de abordar os fenômenos da informação na contemporaneidade em toda sua complexidade, buscando dar um salto qualitativo no plano epistemológico da área. 


\section{Referências}

ALMEIDA, M. A. Mediações da cultura e da informação: perspectivas sociais, políticas e epistemológicas. Tendências da Pesquisa Brasileira em Ciência da Informação, v. 1, n.1, 2008. Disponível em: <http://inseer.ibict.br/ancib/index.php/tpbci/article/view/6/12>. Acesso em: 01 mar. 2010.

ALVAREZ, M. C. Controle social: notas em torno de uma noção polêmica. São Paulo em Perspectiva, v. 18, n. 1, p. 168-176, 2004.

BERGER, P.; LUCKMANN, T. A construção social da realidade. Petrópolis: Vozes, 1974.

CASTELLS, M. A galáxia da internet: reflexões sobre a internet, os negócios e a sociedade. Rio de Janeiro: Ed. Jorge Zahar, 2003.

A sociedade em rede. Rio de Janeiro: Ed. Jorge Zahar,1999.

CARVALHO, R. M. Diários íntimos na era digital: diários públicos, mundos privados. In: LEMOS, A., PALÁCIO S, M (Orgs). Janelas do ciberespaço: comunicação e cibercultura. Porto Alegre: Sulina, 2000.

CORTINA, A.; MARTINEZ NAVARRO, E. Ética. São Paulo: Loyola, 2005.

DAVALlON, J. A mediação: a comunicação em processo? Prisma - Revista de Ciências da Informação e da Comunicação, n. 4, jun. 2007. Disponível em:

$<$ http://prisma.cetac.up.pt/A_mediacao_a_comunicacao_em_processo.pdf $>$. Acesso em: 11 fev. 2010.

DOMINGUES, J. M. Teorias sociológicas no século XX. Rio de Janeiro: Civilização Brasileira, 2001.

DUPAS, G. Ética e poder na sociedade da informação: de como a autonomia das novas tecnologias obriga a rever o mito do progresso. São Paulo: UNESP, 2001.

ELIAS, N. O processo civilizador. Rio de Janeiro: Jorge Zahar, 1990.

GIDDENS, A. As consequências da modernidade. 2. ed. São Paulo: UNESP, 1991.

GOFFMAN, E. A representação do eu na vida cotidiana. 12. ed. Petropólis: Vozes, 2004.

GONZÁLEZ DE GÓMEZ, M. N. A informação como instância de integração de conhecimentos, meios e linguagens. Questões epistemológicas, consequiências políticas. In: ; ORRICO, E. G. D. (Org.) Políticas de memória e informação: reflexos na organização do conhecimento. Natal: EDUFRN, 2006, p. 29-84.

HAMBRIDGE, S. Netiquette guidelines. RFC Editor, 1995. Disponível em: $<$ http://portal.acm.org/citation.cfm?id=RFC1855\&CFID=112334393\&CFTOKEN=94246368 >. Acesso em 21 out. 2010. 
JOÜET, J. Pratiques de communication et figures de la médiation des mídias de masse aux technologies de l'information et de la communication. In: BEAUD, P.; FLICHY, P.;

PASQUIER, D.; QUERÉ, L. (Orgs.) Sociologie de la communication. Paris: Réseaux/CENT, 1997, p. 291-312.

LATOUR, B. A esperança de Pandora: ensaios sobre a realidade dos estudos científicos. Bauru: EDUSC, 2001.

LEMOS, A. Cibercultura: tecnologia e vida social na cultura contemporânea. Porto Alegre: Sulina, 2002.

MARTELETO, R. M.; STOTZ, E. N. (Orgs.) Informação, saúde e redes sociais: diálogos de conhecimentos nas comunidades da Maré. Rio de Janeiro: FIOCRUZ; Belo Horizonte:

UFMG, 2009.

MIÈGE, B. A sociedade tecida pela comunicação: técnicas da informação e da comunicação entre inovação e enraizamento social. São Paulo: Paulus, 2009.

MONTARDO, S., RECUERO, R., AMARAL, A. Blogs: mapeando um objeto. In: CONGRESSO SOBRE HISTÓRIA DA MÍDIA 6., 2008, Niterói. Anais... Niterói: Ed. UFF, 2008. p. 01-19. Disponível em:

$<$ http://pontomidia.com.br/raquel/AmaralMontardoRecuero.pdf $>$. Acesso em 21 out. 2010.

PATALANO, M. Interacción en internet: la net etiqueta en las listas de discusión.

Disponível em:

$<$ http://www.cibersociedad.net/congres2004/grups/fitxacom_publica2.php?idioma=pt\&id=87 $\underline{\text { \&grup }=65}>$. Acesso em 11 set. 2009.

PRIMO, A.; RECUERO, R. A terceira geração da hipertextualidade: cooperação e conflito na escrita coletiva de hipertextos com links multidirecionais. Líbero, v. IX, p. 83-93, 2006.

RECUERO, R. Webrings: As redes de sociabilidade e os weblogs. Sessões do imaginário, Porto Alegre, v. 11, p. 19-27, 2004.

. Redes sociais na internet. Porto Alegre: Sulina, 2009.

SARDINHA, J. Etiqueta na blogosfera. Dicas Blogger, 22 jan. 2008. Disponível em:

$<$ http://www.dicasblogger.com.br/2008/01/etiqueta-da-blogosfera.html > . Acesso em: 21 out. 2010 .

SHEA, V. Netiquette. San Francisco: Albion Books, 1994.

Artigo submetido em: 12 abr. 2011

Artigo aceito em: 30 maio 2011. 